\title{
The Evolution of Extraordinary Eyes: The Cases of Flatfishes and Stalk-eyed Flies
}

\author{
Carl Zimmer
}

Published online: 16 October 2008

(C) Springer Science + Business Media, LLC 2008

The history of life is an unbroken stream of evolution stretching over 3.5 billion years. In order to study it - and in order to describe it - it must be carved into episodes. If scientists want to understand the origin, say, of bats, they do not run experiments to test a hypothesis about how DNA first evolved on the early Earth. They do not do research on the transition from single-celled protozoans to the first animals 600 million years ago. Likewise, they do not get bogged down with bat evolution after bats first evolvedhow, for example, bats spread around the world and how they coevolved with their prey. There is only so much time in the day. Science writers follow the same rules to describe evolution. A newspaper article on the evolution of bats must focus only on that brief episode of life's history. Let its scope grow too large, and it will be too big for a bookor a shelf of books.

This simple necessity can, unfortunately, give people the wrong impression about evolution. We tend to picture evolution as a series of isolated milestones. Once some particular trait evolves, we may assume that evolution simply stops.

The history of eyes is particularly vulnerable to this illusion. Consider, for example, a masterful paper entitled, "Evolution of the vertebrate eye: opsins, photoreceptors, retina, and eye cup," published by Trevor Lamb of Australian National University and his colleagues in the December 2007 issue of Nature Reviews Neuroscience (Lamb et al. 2007). "Here," Lamb and his co-authors announce, "we review a wide range of findings that capture

C. Zimmer $(\square)$

Guilford, CT, USA

e-mail: carl@carlzimmer.com glimpses of the gradations that appear to have occurred during eye evolution, and provide a scenario for the unseen steps that have led to the emergence of the vertebrate eye." They end their review with the emergence of the vertebrate eye. Of course, Lamb et al. (2007) do not mean to imply that the evolution of vertebrate eyes ceased after they first emerged. But their focus is not on what happened afterwards.

Figuring out how a patch of light-sensitive receptors evolved into a camera-like imaging system shared by 40,000-odd species of vertebrates is certainly an important thing to do, and it is a job that will fill many scientists' entire careers. But when the first full-blown vertebrate eyes emerged in some primitive fishes half a billion years ago, the evolution of the vertebrate eye did not stop. The eyes of every vertebrate alive today are different in some important ways from those early eyes. In some cases, the transformation has been exquisitely subtle. But in others, it has been so extreme as to be quite striking.

In this essay, I will look at two animals in which evolution has radically reworked a "standard" kind of eye: flatfishes and stalk-eyed flies. In both cases, eyes have moved far from their original position on the head. But flatfishes and stalk-eyed flies are not just freakish codas on the symphony of evolution. Instead, they are remarkable illustrations of some of the most powerful forces shaping all life, weird or otherwise.

Flatfishes - such as flounder, turbot, and plaice-are among the most striking animals in the sea. They spend much of their adult life sideways, hugging the sea floor where they lie in wait to ambush smaller fish. Their anatomy and DNA both reveal that they belong to the most diverse radiation of vertebrates today, known as the teleosts. Teleosts include most of the fishes we are most familiar with, such as goldfish and trout. In many respects, flatfishes have a standard teleost body plan. But as they 
have adapted to life on the sea floor, some new traits have evolved. All vertebrates, ourselves included, use hair cells in the inner ear to keep ourselves balanced. In most flatfish species, the hairs have changed orientation to match the orientation of their bodies. (Schrieber 2006). Many flatfishes can camouflage the upward-facing side of their body. The underside is pale, and in many species the fin on the underside is tiny.

And then, of course, there are the eyes.

On a typical teleost, such as a goldfish, the eyes face out from either side of the head. On a flounder, both eyes sit on one side, gazing upwards. It takes time for this Picasso-esque anatomy to emerge: flatfishes are born with eyes in the normal position, but as they grow, one eye moves across its head to join its partner. To accommodate this migrant, the bones of the flatfish head twist and turn to make room.

When Charles Darwin published the Origin of Species in 1859 , a number of critics took him on, but none more seriously than a British zoologist named St. George Jackson Mivart. In 1871, Mivart published a full-scale challenge to evolution by natural selection, called On the Genesis of Species. In one of his attacks, Mivart wielded the flatfish:

In all these fishes the two eyes, which in the young are situated as usual one on each side, come to be placed, in the adult, both on the same side of the head. If this condition had appeared at once, if in the hypothetically fortunate common ancestor of these fishes an eye had suddenly become thus transferred, then the perpetuation of such a transformation by the action of "Natural Selection" is conceivable enough. Such sudden changes, however, are not those favoured by the Darwinian theory, and indeed the accidental occurrence of such a spontaneous transformation is hardly conceivable. But if this is not so, if the transit was gradual, then how such transit of one eye a minute fraction of the journey towards the other side of the head could benefit the individual is indeed far from clear. It seems, even, that such an incipient transformation must rather have been injurious. (Mivart 1871)

How exactly a transitional flatfish eye would have hurt the animal, Mivart did not say. In general, Mivart was more interested in the fact that intermediate forms of traits did not seem to be useful. What good was half a wing to a bird, he wondered. What good was an eye that had not made it all the way around a flatfish's head?

Darwin took Mivart very seriously, and in 1872-the year after On the Genesis of Species came out-he took on Mivart's arguments in the sixth edition of the Origin of Species. Mivart, Darwin argued, was not thinking carefully enough about what could or could not evolve by gradual evolution. Darwin agreed that flatfishes did not evolve in a sudden change. But he could envision a way in which the fish could have evolved in a series of steps. He had read how young flatfishes-with normal eyes-sometimes fall to the sea floor and then twist their lower eye upward to see above them. They seem to strain their lower eye, twisting it as far as possible.

At this point in his life, Darwin was warming to Jean Lamarck, the French naturalist who had proposed an earlier theory of evolution in 1800. Lamarck had argued that an animal's body changed through its experiences, and that those changes could be passed down to its offspring. Natural selection, Darwin's great discovery, depended instead on pure inheritance. Nothing we do in our lives changes the inherited traits we pass down to our offspring. But Darwin struggled with the mystery of heredity. Over time, he became more open to Lamarck. And so he offered a surprisingly Lamarckian explanation of creeping flatfishes' eyes. The more the young flatfishes strained their lower eyes, he suggested, the more it migrated during its development towards the other side. He wrote,

We thus see that the first stages of the transit of the eye from one side of the head to the other, which Mr. Mivart considers would be injurious, may be attributed to the habit, no doubt beneficial to the individual and to the species, of endeavouring to look upward with both eyes, while resting on one side at the bottom. (Darwin 1872)

Natural selection had driven the eye further, Darwin proposed. "For all spontaneous variations in the right direction will thus be preserved; as will those individuals which inherit in the highest degree the effects of the increased and beneficial use of any part. How much to attribute in each particular case to the effects of use, and how much to natural selection, it seems impossible to decide."

By the early 1900s, as scientists began to understand how genes work, they realized that mutations could fuel natural selection. But some biologists still argued that evolution might proceed by giant leaps. In the 1930s, the German biologist Richard Goldschmidt pointed to rare cases in which animals were produced with dramatic changes to their bodies. He called them "hopeful monsters," and suggested that in some cases they might happen to be well suited to their environment. For Goldschmidt, flatfishes looked like promising candidates for hopeful monsters (Goldschmidt 1933). After all, he pointed out, no one had found a transition between ordinary fishes and flatfishes. Perhaps, Goldschmidt suggested, it had only taken a single mutation to launch a fish eye on its journey across the skull, and the basic flatfish anatomy emerged in a flash.

In 2008, a graduate student at the University of Chicago named Matt Friedman discovered compelling evidence that the flatfish eye evolved not in a single jump, but in a series 
of steps. He discovered a fossil that Mivart claimed could not exist - a proto-flatfish with a transitional eye (Friedman 2008).

Friedman made the discovery while researching his dissertation on the diversity of teleosts. One day, as he paged through a book on fish fossils, he noticed a 50million-year-old specimen called Amphistium. Like many fish fossils, this one only showed the bones from one side of the animal. It was generally agreed that Amphistium belonged to some ordinary group of teleosts, although biologists argued over which one. But Friedman saw something different. To him it looked like a flounder. He was struck not by its eyes (the fossil was not preserved well enough for Friedman to see clearly what its eyes were like). Instead, he noticed subtler traits on Amphistium found only on flatfishes. All flatfishes, for instance, have spines on some of their vertebrae that bow forward in a peculiar and distinctive way. So does Amphistium.

To see if he was right, Friedman began traveling to museums around Europe to look at their Amphistium fossils. When he found an intriguing specimen still encased in rock, he had it run through a CT scanner so that he could see its skull. He discovered that Amphistium shares many traits with flatfishes found in no other fish. Most striking of all Amphistium's anatomy was its pair of eyes. On one side, the eye sat in its normal teleost position. But on the other side, the eye sat high on the fish's head. In other words, this was a fish Mivart had said could not have existed (Fig. 1).

This was not a freakish deformity, Friedman realized as he looked at more and more Amphistium fossils. And since they were adult fish, not juveniles, the fossils could not be showing developing eyes still drifting from one side to the a

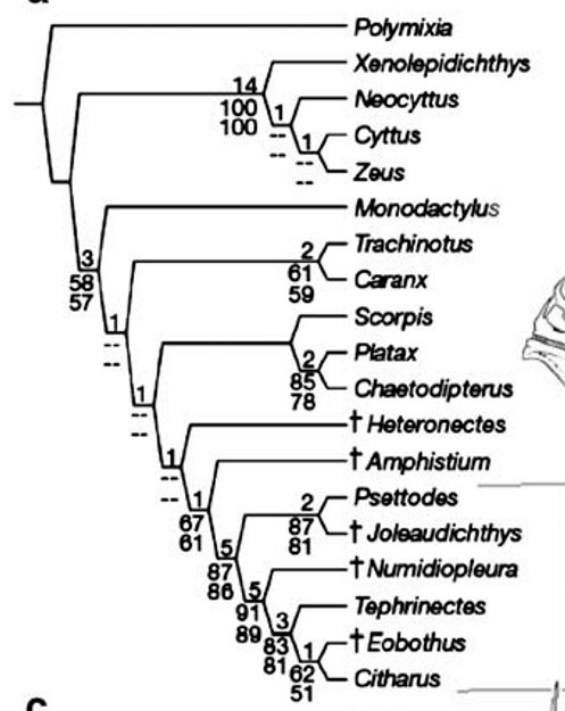

。

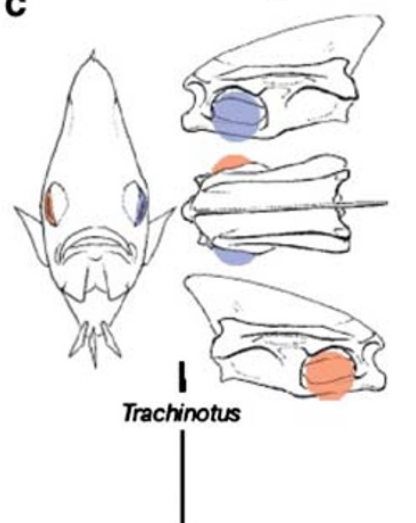

b
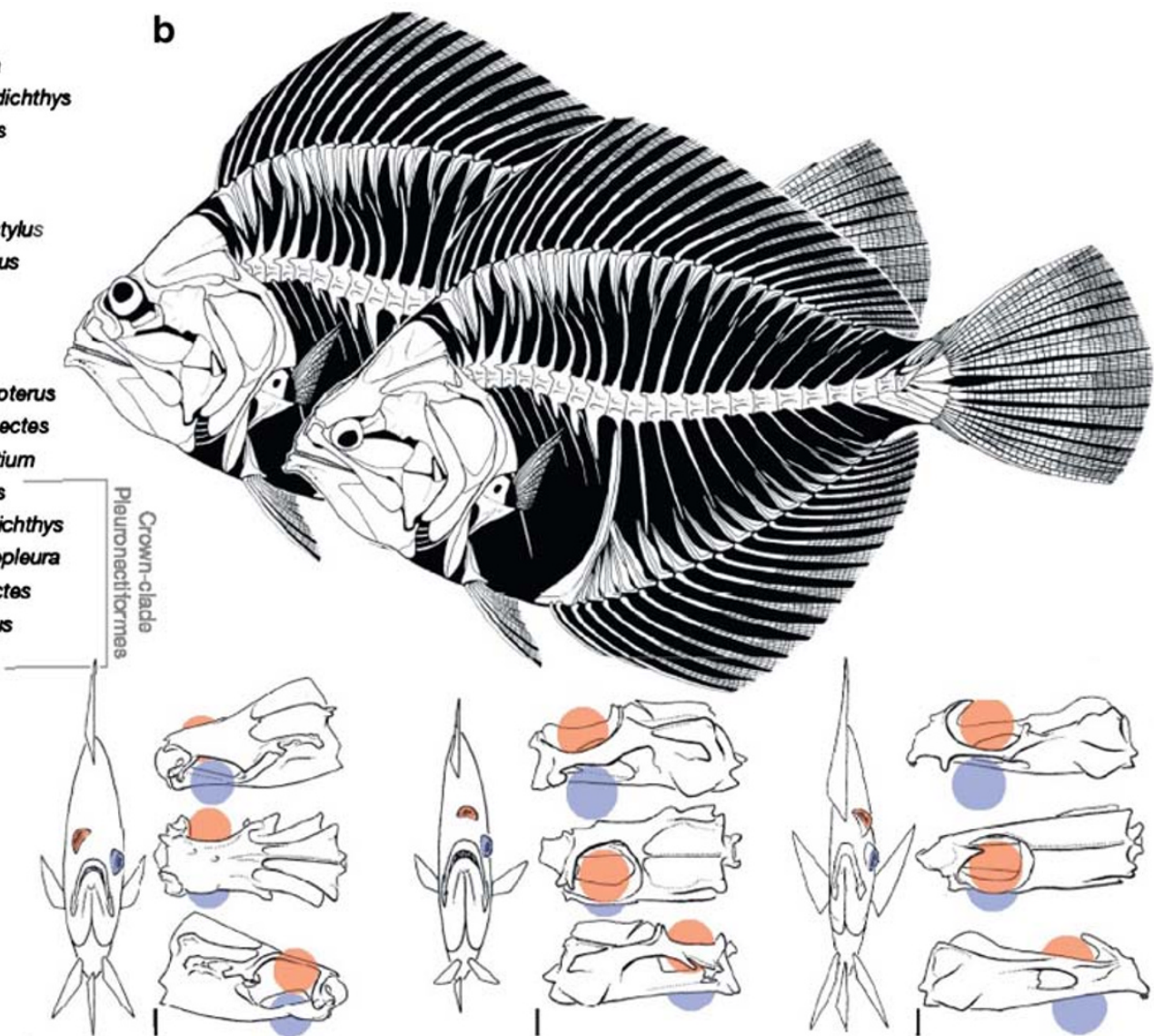

†Amphistium/†Heteronectes

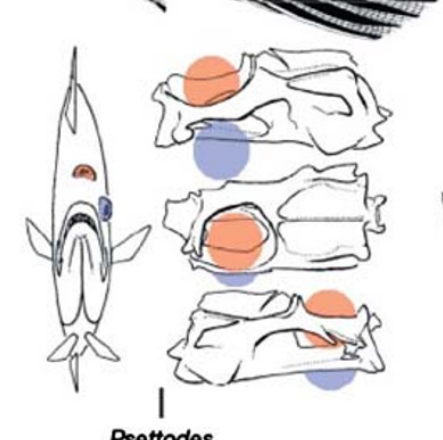

Psettodes

Orbit eclipses dorsal midline

Orbital migration

T

Fig. 1 Newly described fossils shed light on the evolution of flatfish eyes. a A comparison of living flatfishes to other living and extinct species led to this evolutionary tree. "Crown-clade Pleuronectiformes" are the living species of flatfishes. b A reconstruction of Amphistium, the closest relative to living flatfishes, shows the intermediate position of one of its eyes. c A simplified version of the evolutionary tree in (a) illustrates the transition. To the right of each fish are three views of its skull, with the position of its eyes marked in red and blue. Reprinted by permission from Macmillan Publishers Ltd: Nature, 454 (7201):209-12, copyright 2008 
other. Intriguingly, though, some Amphistium had a higher left eye, while others had a higher right eye. In most living flatfishes, each species only develops its eyes on one side or the other.

Friedman also wondered if Amphistium was not a transitional early flatfish, but instead a flatfish that had evolved an eye that had moved back to its original side. But he was able to reject that possibility when he traveled to Vienna to look at another Amphistium fossil. It turned out not to be Amphistium at all, but a separate species altogether. He named it Heteronectes (meaning "different swimmer").

Heteronectes lived around the time of Amphistium, and it also had many traits shared only by flatfishes. It also had one eye sitting high on its head. But a careful comparison of Heteronectes to living and fossil fish revealed that it was missing some traits found only in Amphistium and living flatfishes. In other words, Heteronectes, Amphistium, and living flatfishes all share a close common ancestor. Heteronectes belongs to the first lineage to branch off from that ancestor. Later, the ancestors of Amphistium and living flatfishes split. That is, the two oldest branches of flatfish relatives had the same intermediate eyes (Fig. 1).

In a common ancestor of Heteronectes, Amphistium, and living flatfishes, Friedman argues, one eye began to move upward. Friedman proposes that at this early stage, protoflatfishes were lying on the sea floor at least some of the time. They propped themselves up a bit with their downward-facing fins, so that they could see a little with their downward-facing eye. Mutations arose that produced eyes sitting higher on their heads. Natural selection might have favored them because they gave the fish better vision. Even with one eye midway up their head, the early flatfishes thrived as predators. (Friedman found one fossil of Amphistium with the skeleton of another fish in its gut.)

A fish in Lake Malawi in Africa called Nimbochromis livingstonii may offer a clue to this early stage of flatfish evolution. To catch its prey, it lies on one side on the lake bottom pretending to be dead. White blotches on its flank add to the illusion, because they look like fungi feeding on a dead fish. Unsuspecting fish swim by, whereupon Nimbochromis bursts from the lake bottom to engulf them (McKaye 1981).

But flatfish evolution did not grind to a halt once both eyes ended up on the same side of the head. It turns out there is a living fossil flatfish on Earth today, known as Psettodes. (There are three species in this genus, found in the Atlantic, Indian, and Pacific Oceans.) The ancestors of Psettodes branched off from all other living flatfishes long ago. Intriguingly, some Psettodes put both eyes on their left side and some on their right - the same loose variations found in fossil flatfishes. They even swim vertically like other teleosts, because they have fins on both sides of their bodies. Friedman argues that the full-blown flatfish body did not emerge until after Psettodes branched off-more evidence of the steps by which this weird kind of creature evolved.

The lesson of the flatfish is the same kind of lesson emerging from research on other evolutionary transitions. Fish did not suddenly leap onto land, equipped with legs and toes and other adaptations to life out of the water. A lineage of fish gradually evolved parts of the tetrapod body plan, initially while they were still aquatic vertebrates (Shubin 2008). And after tetrapods began to walk on land, new adaptations continued to emerge for many millions of years, such as the amniote egg that allowed one lineage of tetrapods to lay their eggs on dry land. Whales evolved between 50 and 40 million years ago, but they did not leap back in the water, shedding their legs and sprouting flukes in a sudden evolutionary jolt. Instead, a lineage of mammals gradually became more and more adapted to life in the water. Ten million years after whales first shifted to the water, when they reached $50 \mathrm{ft}$ long and never returned to land in their lives, whales still had tiny rear legs complete with toes (Zimmer 1998).

Flatfish eyes also offer a lesson in convergent evolutionthe way in which separate lineages independently arrive at similar solutions to the same biological problem. Convergent evolution is a striking combination of similarities and differences. Organisms are often prevented from evolving into identical forms by developmental constraints and by the contingencies of their evolutionary history. Flatfishes are not the only fish that have evolved flat bodies for swimming on the sea floor. Rays have as well, and like flatfishes, they have eyes on the upper surface of their bodies. But rays do not have migrating eyes. Instead, they evolved a flat body by expanding their pectoral fins, which they use to "fly" underwater much like birds use their wings to fly in the air. Their eyes simply tilted upwards from the sides of their heads.

Flatfishes, on the other hand, did not have that option. Their teleost ancestors were flattened from side to side. The easiest path to a flattened lifestyle was to flop over on one of their sides. As a result, the only way to get both eyes looking upward was for one of them to migrate (Dawkins 1986).

Vertebrate eyes are, of course, not the only kind of eye in the animal kingdom. The millions of insects, crustaceans, and other arthropods on Earth share a very different kind of organ for capturing light to detect objects. From one species to the next, the basic anatomy of the arthropod eye is pretty much the same. Hundreds or thousands of columns develop into a tightly packed grid on either side of an arthropod's head. Each column can only detect light from a narrow portion of an arthropod's field of vision. But the arthropod brain can combine the signals from all of them to perceive large-scale patterns - like an oncoming fly swatter. 
Once the arthropod eye evolved roughly 530 million years ago, it also took on some weird forms. In several lineages of insects, for example, an eyestalk evolved. The best-studied case of insect eyestalks can be found in a family of flies called Diopsidae, or the stalk-eyed flies (Chapman et al. 2005). There are hundreds of species of stalk-eyed flies, mostly in the tropics of the Old World, and if you ignore their heads, they look like relatively ordinary flies, with six legs and folding wings. But ignoring their heads is impossible. Their eyes sit on wand-like appendages, in some cases stretching out longer than the animal's entire body. (Fig. 2).

Like the flounder, the stalk-eyed fly starts out life looking a lot like its ordinary relatives (Warren and Smith 2007). It hatches from an egg and develops as a larva. The larva then becomes a pupa, encasing itself in a shell inside of which it will develop into its adult form. Two patches of cells at the front end of the pupa begin to express a distinctive set of eye-building genes - the same kinds of genes that switch on in other flies, such as Drosophilia melanogaster. Eye cells begin to develop on these patches, and neurons begin to link them to the brain-again in a process much like that in a Drosophila head.

But in stalk-eyed flies, these neurons begin to grow rapidly, while surrounding cells form a sleeve of cuticle that will become the stalk. Trapped inside the puparium, the lengthening eye stalks are forced to grow into tight coils (Buschbeck and Hoy 2005). When the fly finally emerges, it begins to pump fluid into its stalks, unfolding them to their full extent over the course of about $15 \mathrm{~min}$.

The eyes of stalk-eyed flies are more like spheres than the bulging disks of typical insects. They are covered with facets that can receive light from all directions (stalk-eyed flies have 2,000 facets on their eyes, almost three times more than on Drosophila's). Stalk-eyed flies have some binocular vision where the fields of their two eyes overlap.

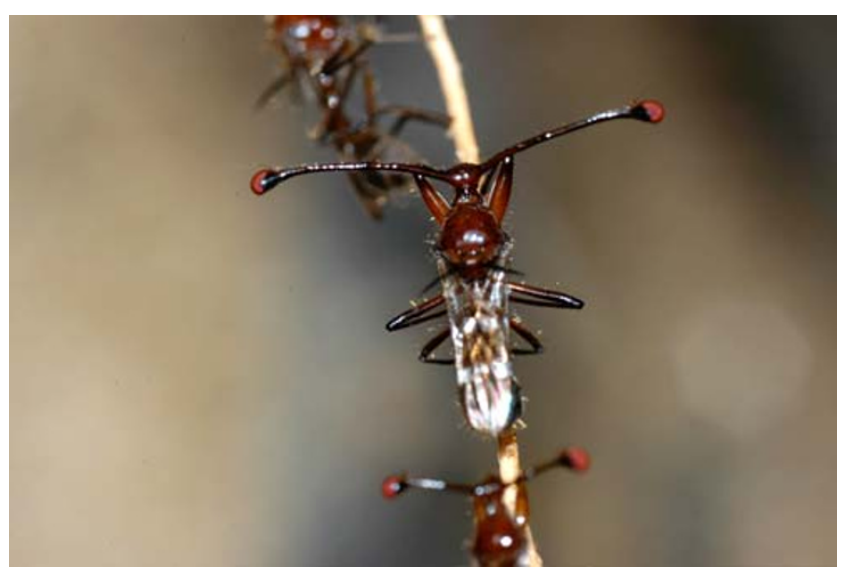

Fig. 2 Stalk-eyed flies, such as Cyrtodiopsis dalmanni shown here, have evolved bizarre eyes through sexual selection. Photo courtesy of Gerald Wilkinson, University of Maryland
But the longer the stalks, the smaller that field becomes. Experiments also show that long eyestalks make it harder for the flies to maneuver in flight. You do not see a lot of fighter jets with enormous bendable beams sticking from either side of the cockpit. Studies at the University of North Dakota have shown that stalk-eyed flies can only turn about 860 degrees per second. Other flies can turn 2,000 degrees (Ribak and Swallow 2007).

Stalk-eyed flies have eyes as strangely transformed as flatfishes'. The question naturally arises, how did stalk eyes evolve? The flies have had them for a long time-stalkeyed flies trapped in amber date back about 50 million years. Some scientists have proposed that the eyes first began to stretch out from the head because natural selection favored flies with better peripheral vision. But it is clear that another force soon came into play: sexual selection.

Stalk-eyed flies typically flit around moist undergrowth during the day, but at night they congregate in roosts on rootlets and leaves. As they gather, fights break out. Males try to eject one another from the groups. They rear up and spread their front legs out alongside their eyestalks, kicking each other to try to knock them over. Males with bigger eyestalks tend to win these fights; some evidence even suggests that males measure each other up by comparing eyestalks, and the male with the smaller eyestalks backs down. Before dawn, the remaining males mate with the females in a group. At this point, the eyestalks play another role in the sex life of stalk-eyed flies: it turns out that females prefer to mate with males with longer eyestalks.

Both lines of evidence suggest that stalk eyes evolved in the same way Darwin argued antlers on deer and bright plumage on birds had evolved. They are the result of competition for mates, rather than a competition to survive. Since male flies with longer eye stalks reproduce more offspring than other males, they pass down their genes, making the average eye stalks longer in the next generation.

But why should a female favor long eye stalks in the first place? Three potential explanations look promising, based on the evidence scientists have gathered so far. The ultimate answer may turn out to be a combination of some of these explanations or even all three.

The first possibility is that eye stalks give females a reliable signal of a male's genetic quality. It takes a lot of energy to build eye stalks, and when male flies with small eye stalks starve, they can only make tiny ones. Male flies with long stalks barely shrink their stalks at all. If females evolve an attraction to males with long eye stalks, they will be more likely to endow their offspring with stress-resistant genes from their father-ensuring the long-term success of her own genes.

The second possibility is that males are advertising another kind of gift: a way to fight against parasites. These parasites are not tapeworms or viruses or other organisms 
you might be familiar with. They are parasitic genes in stalk-eyed fly DNA. Female stalk-eyed flies in some populations carry a peculiar segment of DNA on their X chromosomes known as a sex-ratio distorter. The flies pass this DNA on to their offspring, and in their sons, the sexratio distorter genes kill off sperm cells with $\mathrm{Y}$ chromosomes in them. All that remain are sperm with $\mathrm{X}$ chromosomes carrying the sex-ratio distorter. When these males mate, they only produce daughters, which also carry the sex-ratio distorter. The sperm-killing ability of sex-ratio distorters means that, over a few generations, a population of stalk-eyed flies can become made up mostly of females, most of which carry sex-ratio distorters.

It turns out that males with long eyestalks also carry DNA on their $\mathrm{X}$ chromosomes that can suppress sex-ratio distorters. Females that choose a long-stalked male will also be choosing sperm that can produce both males and females. In a population dominated by females, males have an evolutionary edge, because each male can mate more often and leave more offspring. So it pays for the female flies to choose mates that will give them sons. Having long eye stalks and suppressor genes might not seem to have much in common. But it turns out that the DNA for both traits sit very close to each other on the male stalk-eyed fly $\mathrm{X}$ chromosome. If you get one, you get the other (Presgraves et al. 1997; Johns et al. 2005).

The third possibility is that long eye stalks signal fertility to females. When females mate with long-stalked males, they tend to produce more offspring than when they mate with other males. Another intriguing clue is the fact that males with long eye stalks also have long sperm (Johns and Wilkinson 2007). Female flies that mate with several males may be able not only to select which males to mate with but which male's sperm to fertilize their eggs. Long-stalked eyes may just be one of many signals the females use to boost their reproductive success.

In both flatfishes and stalk-eyed flies, an ancient kind of eye has been transformed in recent evolutionary history. In both cases, the eye's evolution has not been driven simply by the benefits of better vision. The eye has been dragged, stretched, and otherwise altered to accommodate other changes to the lives of fishes and flies. As marvelous as these eyes may be in their intricacy and power, in these recent transitions, they have just been along for the ride.

\section{References}

Buschbeck EK, Hoy RR. The development of a long, coiled, optic nerve in the stalk-eyed fly Cyrtodiopsis whitei. Cell Tissue Res 2005;321(3):491-504. doi:10.1007/s00441-005-1142-4.

Chapman T, Pomiankowski A, Fowler K. Stalk-eyed flies. Curr Biol 2005;15(14):R533-5. doi:10.1016/j.cub.2005.07.015.

Darwin C. On the origin of species by means of natural selection; or, The preservation of favored races in the struggle for life. 6th ed. New York: Appleton; 1872.

Dawkins R. The blind watchmaker: why the evidence of evolution reveals a universe without design. New York: Norton; 1986.

Friedman M. The evolutionary origin of flatfish asymmetry. Nature 2008;454(7201):209-12. doi:10.1038/nature07108.

Goldschmidt R. Some aspects of evolution. Science 1933;78 (2033):539-47. doi:10.1126/science.78.2033.539.

Johns PM, Wilkinson GS. X chromosome influences sperm length in the stalk-eyed fly Cyrtodiopsis dalmanni. Heredity 2007;99 (1):56-61. doi:10.1038/sj.hdy.6800963.

Johns PM, Wolfenbarger LL, Wilkinson GS. Genetic linkage between a sexually selected trait and $\mathrm{X}$ chromosome meiotic drive. Proc Biol Sci 2005;272(1576):2097-103. doi:10.1098/rspb.2005. 3183.

Lamb TD, Collin SP, Pugh EN Jr. Evolution of the vertebrate eye: opsins, photoreceptors, retina and eye cup. Nat Rev Neurosci 2007;8(12):960-76. doi:10.1038/nrn2283.

McKaye KR. Field observation on death feigning: a unique hunting behavior by the predatory cichlid, Haplochromis livingstoni, of Lake Malawi. Environ Biol Fish 1981;6:361-5.

Mivart, St George Jackson. On the genesis of species. New York: Appleton; 1871.

Presgraves DC, Severance E, Wilkinson GS. Sex chromosome meiotic drive in stalk-eyed flies. Genetics 1997;147(3):1169-80.

Ribak G, Swallow JG. Free flight maneuvers of stalk-eyed flies: do eye-stalks affect aerial turning behavior. J Comp Physiol A Neuroethol Sens Neural Behav Physiol 2007;193(10):1065-79.

Schrieber AM. Asymmetrical craniofacial remodeling and lateralized behavior in larval flatfish. J Exp Biol 2006;209:610-21. doi:10.1242/jeb.02056.

Shubin N. Your inner fish: a journey into the 3.5-billion-year history of the human body. New York: Pantheon; 2008.

Warren I, Smith H. Stalk-eyed flies (Diopsidae): modelling the evolution and development of an exaggerated sexual trait. Bioessays 2007;29(3):300-7. doi:10.1002/bies.20543.

Zimmer C. At the water's edge: macroevolution and the transformation of life. New York: Free Press; 1998. 